\title{
A PRINCIPIOLOGIA ÉTICA COMO BALISA NA ELABORAÇÃO DE UM PROJETO ACADÊMICO DE PESQUISA
}

\author{
Israel Batista França Junior ${ }^{1}$ \\ Jussara Maria Moreno Jacintho
}

\section{RESUMO:}

O presente artigo aborda a questão da ética exigida na elaboração de trabalhos acadêmicos em uma sociedade global e complexa. Parte-se da ética comportamental exigida para os indivíduos comuns em suas relações humanas, para se chegar ao âmbito da produção e divulgação do conhecimento em áreas profissionais, na criação artística e intelectual na elaboração de trabalhos acadêmicos, principalmente na era da tecnologia que exerce papel facilitador e, concomitantemente, ferramenta de controle de titularidade e configuração de plágio. E por fim, busca-se justificar o emprego das regras da ABNT não só por exigência legal.

Palavras-chave: Ética; Trabalho acadêmico; Regras da ABNT

\section{THE PRINCIPLES OF ETHICS AS A BEACON IN THE PREPARATION OF AN ACADEMIC RESEARCH PROJECT}

\begin{abstract}
:
This article addresses the question of the ethics required in the elaboration of scholarly works in a global and complex society. It starts from the behavioral ethics required for individuals in their human relations, to reach the scope of production and dissemination of knowledge in professional areas, artistic and intellectual creation in the elaboration of academic works, especially in the era of technology that plays a role Facilitator and, concurrently, tool for control of ownership and configuration of plagiarism. And finally, we seek to justify the use of the ABNT rules not only by legal requirement.
\end{abstract}

Keywords: Ethic; Academic work; ABNT rules

\section{INTRODUÇÃO}

Em todos os campos da convivência humana os comportamentos morais e éticos guiam as relações. De modo que, para que haja harmonia entre as pessoas, bem como entre indivíduos e instituições. Muito mais se exige numa sociedade em franco desenvolvimento, globalizada e complexa que valoriza de sobremaneira a propriedade.

\footnotetext{
${ }^{1}$ Mestrando em Direito pela UFS, Pós-Graduado em Direito Tributário e Auditoria Fiscal pela UFS, Graduado em Direito pela Universidade Tiradentes - UNIT e Auditor Técnico de Tributos do Estado de Sergipe.

${ }_{2}^{2}$ Doutora em Direito Constitucional pela PUC/SP, mestre em Direito pela UERJ, especialista pela FGV/RJ, Prof. ${ }^{a}$ de Direito Constitucional na UFS, no Mestrado em Direito-UFS e no Mestrado-Rede Profiap.
} 
Tomando como foco as relações entre indivíduos e instituições, o presente trabalho busca discutir a ética como regra norteadora da vida acadêmica, notadamente na elaboração de trabalhos acadêmicos (textos, pesquisas etc.), pode ser considerada adequada e exemplar para que o discente obtenha êxito. Diante do que se questiona: qual o papel da ética na elaboração de um trabalho acadêmico? A ética visa tão somente o direito material da propriedade de uma pesquisa ou o respeito à titularidade intelectual de uma obra?

Inicialmente, será analisada a ética comportamental exigida para os indivíduos comuns em sociedade e suas mais elementares condutas nas relações humanas, com base em diferentes preceitos morais e éticos. Em seguida, refletir-se-á sobre o critério ético que se exige na área médica, com sua peculiaridade de tratar da vida humana; bem como na atividade de criação artística e intelectual para embasar a discussão sobre a ética necessária na elaboração de trabalhos acadêmicos, com suas implicações para o discente, o orientador e a instituição. Essa discussão sobre a produção acadêmica passa pela adoção da internet como uma ferramenta facilitadora de pesquisa e de acesso à informação em âmbito mundial, como bibliotecas, universidades, museus, sites especializados nas mais diversas áreas científicas.

Diante desse quadro, investigar-se-á como essa ferramenta incrementa e acelera a pesquisa acadêmica, facilitando o acesso aos diversos trabalhos científicos em todas as áreas sociais, humanas e científicas. Em contrapartida, também questiona como isso reflete no controle de titularidade/autoria de trabalhos acadêmicos para a configuração de apropriação ilegítima da titularidade de uma ideia, pesquisa ou trabalho acadêmico - o suposto plágio. Por derradeiro, verificar-se-á se é possível explicar o uso das regras da Associação Brasileira de Normas Técnicas - ABNT como norma que assegura a concretização do fundamento ético exigido de todo discente na elaboração de trabalhos acadêmicos.

\section{A ÉTICA NA CONVIVÊNCIA HUMANA}

Um dos princípios da organização da vida em sociedade é a exigência de que seus membros convivam com responsabilidades recíprocas. Segundo Nader (2016, p. 43), nas relações intersubjetivas surgem as responsabilidades moral, jurídica, religiosa e social. Muito embora somente a jurídica possa exercer a coercibilidade, as outras de caráter extrajurídico (moral, religiosa ou convencional) acarretam constrangimento. Dado ao seu caráter volúvel, cambiante e mutável, conceitua-la torna-se tarefa complexa. Para Santos (2015, p. 4) "a ética 
consiste em algo que muda conforme a sociedade, a época, os conceitos e até conforme o grupo em que os indivíduos participam”.

Nessa linha da ética como sentimento social, ensina Bittar (2016, p. 25) que "a ética corresponde ao exercício social de reciprocidade, respeito e responsabilidade" e que enquanto exercício de humanidade, nos ratifica na condição de seres que convivem, aprendem e permutam valores, que serão próprios e adequados de cada época, povo, comunidade e país. São esses valores que determinam o que seja o bom, o justo e ideal para cada contexto social correspondente.

Em última análise, o pressuposto máximo de toda sociedade deve ser a promoção do bem estar de seus membros. Assim, ao longo do desenvolvimento humano, não é possível imaginar uma sociedade ou aglomeramento humano que não tenha norteado sua convivência e até preservação, afastando-se de critérios morais e éticos. Isso porque, todo agrupamento humano, dos mais simples (família, clube recreativo, associações comunitárias), aos mais complexos (sindicatos, entidades de classes, instituições de ensino, instituições religiosas, administrativas e o Estado) se norteiam por códigos de ética.

Aliás, em sentido contrário ao que aqui se pretende demonstrar, de uma ética em prol da harmonia social, até mesmos nas sociedades em que a presença estatal seja considerada incipiente ou ausente, a exemplo de comunidades localizadas em morros e favelas, onde pressupõe inexistente o regramento dos comportamentos sociais, as condutas dos seus indivíduos são avaliadas e severamente reprimidas por quem comanda esses territórios. ${ }^{3}$

Hume (1995, p. 70) já havia dito que até mesmo nas sociedades em que estão estabelecidas sobre os princípios mais imorais e destrutivos são exigidas certas normas que, como uma espécie da "falsa honra" ou como interesse privado, coage os membros a observar. Por exemplo, os assaltantes e piratas não podem manter suas maléficas associações se não houver um modelo de justiça distributiva que todos aceitem. Levando esse raciocínio ao extremo, Hume (1995, pp. 72-73) afirma “[...] que nem sequer é possível aos homens matarem-se uns aos outros sem estatutos e princípios e sem uma ideia de honra e justiça."

\footnotetext{
${ }^{3}$ Por exemplo, são notórios os "julgamentos" feitos por "tribunais" do tráfico, conforme noticiado pela imprensa, em que integrantes de facções rivais são submetidas a torturas e assassinadas. Um caso de bastante repercussão foi a morte do jornalista da Rede Globo Tim Lopes, ocorrida em 02 de junho de 2002, quando o mesmo investigava abuso de menores e tráfico de drogas, foi capturado, submetido a tortura e morto, após ser julgado por traficantes da Vila Cruzeiro, na Penha no Rio de Janeiro. Essa notícia consta no Jornal Estadão do dia 09 jun. 2002. Disponível em: < http://brasil.estadao.com.br/noticias/geral,reporter-foi-capturado-torturado-emorto-por-traficantes,20020609p17850>. Acesso em: 12 out. 2016.
} 
Assim, diferentes grupos sociais enumeram condutas morais que passam a reger os comportamentos individuais em suas comunidades.

Foucault (1984, p. 26) compreende que a moral tanto pode ser entendida como um conjunto de valores e regras de agir indicadas aos sujeitos e aos grupos por meio de aparelhos prescritos como família, instituições educativas, igrejas etc., de forma explicita ou difusa, como também através do "[...] comportamento real dos indivíduos em relação às regras e valores que lhe são propostos." Porém, com a faculdade de obedecer ou resistir, respeitar ou negligenciar esses valores propostos. O estudo dessa análise de variante ou de violação do sistema prescritivo em dada cultura, do qual os indivíduos têm consciência relativa, se caracteriza como um fenômeno denominado de moralidade dos comportamentos.

Talvez essa faculdade tenha se intensificado na sociedade moderna, com a aparente deficiência de comportamentos morais. Fonseca (2003, p. 139) ao comentar a obra Historia da Sexualidade de Michel Foucault, faz nítida separação quanto ao aspecto ético entre a constituição do homem antigo e do homem moderno. Enquanto a ética é o elemento capital na constituição do sujeito antigo, a marca principal do sujeito constituído no presente é exatamente a carência da ética. Para o autor "o sujeito moderno, sendo produto da normalização empreendida pela disciplina, não tem, no processo de sua constituição, a marca da relação que caracteriza a ética." Assim, o indivíduo moderno, constituído pela norma, se diferencia do sujeito antigo, formado pela ética.

Afastando essa ideia do tudo ou nada, defende-se não só um sujeito de acordo com a norma, mas, também um sujeito moral. Evidentemente reconhecendo que a sociedade urbanoindustrial demanda atividades policiais, com Código Civil, Penal, de Trânsito e várias outras normatizações, todavia “[...] a ética não pode ser reduzida a uma codificação, mas precisa ser um constante exercício de inventividade e adequação - algo mais teórico do que códigos morais" (MORAIS, 2013, pp. 83-84).

Para Foucault (2001, p. 28) uma ação moral implica à sua própria realização, além de que, visa também à construção de comportamento moral que leva o indivíduo, não só a atuações de acordo com os valores e às normas, mas também a determinada forma de ser característica do sujeito moral. Uma ação para ser considerada moral, não se reduz ao simples ato ou série de atos em conformidade com uma regra, lei ou valor, mas uma relação em si, não sendo esta uma mera consciência de si, mas constituição de si mesmo enquanto sujeito moral. 
O indivíduo entende-se como parte que constitui o próprio objeto do ato moral e define para si o modo de ser válido como realização moral de si mesmo.

Nesse aspecto, o sujeito moral se assemelha à atitude ética praticada por responsabilidade, da qual falou Max Weber (2007, p. 113) para quem toda atividade realizada sob a égide da ética pode ser subordinada sob dois aspectos diversos e opostos: a ética da responsabilidade ou a ética da convicção. Assim, quem age de acordo com a ética da responsabilidade, analisará e assumirão as fraquezas comuns dos homens, as consequências previsíveis advindas dos atos aos quais foram imputadas em razão de suas próprias ações. De outra parte, quem age de acordo com a ética da convicção, não atribuirá a responsabilização a si mesmo, mas a outros, como o mundo, à burrice dos homens ou à vontade de divina.

Na linha de compreensão de Locke (2000, pp. 46-47) "as ações dos homens nos convencem que a regra da virtude não consiste em seu princípio interior”. Acrescenta que se quisermos aceitar de forma cortes e sincera a respeito da profissão da maioria dos homens e pensarmos que seus atos interpretam seus pensamentos descobriremos que eles não têm tal veneração interna por estas regras, nem a completa convicção de sua certeza e obrigação.

E nessa análise de atuação do indivíduo social, pode-se chegar à conclusão de que não há como formular uma lista determinada de valores e princípios éticos universais ou para determinada sociedade em numerus clausus, posto que ao término da referida lista não mais subsistem os correspondentes preceitos. A ética se constitui em uma autoanálise ou autocrítica permanente de um agir em comunidade, em sintonia com essa mesma sociedade.

Entretanto, se hipoteticamente, pudesse existir um grupo social que tivesse como lema a falta de ética de seus membros, esse grupo jamais se perpetuaria, visto que não haveria confiança, negociações, contratos, respeito aos direitos objetivos e subjetivos uns dos outros. Em suma, regras básicas finalísticas para a existência de toda e qualquer sociedade é que se busque a felicidade de seus membros.

\section{A ÉTICA NAS ATIVIDADES LABORAIS}

Como a ética é essencial para a convivência humana, o exercício de qualquer atividade profissional também requer condutas morais e éticas estabelecidas como ocorre na atividade empresarial, na advocacia, na magistratura, no ministério público, na administração pública e na docência. 
Hoje não se nega que a ética seja necessária na área comercial. É corrente majoritária que o empreendedor deve exercer suas atividades tendentes à obtenção do lucro, todavia, deve respeitar o consumidor, os fornecedores, os colaboradores, o meio ambiente, que orientam os critérios éticos a serem adotados pelo profissional com responsabilidade social. Nesse sentido, a Norma Nacional - ABNT NBR 16001:2004, ${ }^{4}$ que certifica as empresas quanto à responsabilidade social, tem como escopo estabelecer requisitos mínimos de gestão responsável socialmente, possibilitando às organizações a implementação de políticas que incentivem um comprometimento ético. Até porque para manter a boa imagem, nenhuma empresa quer ter seu nome atrelado a falcatruas, negociatas, sonegações ou práticas desleais.

Na advocacia, o Conselho Federal da Ordem dos Advogados do Brasil instituiu o Código de Ética e Disciplina ${ }^{5}$ para nortear o advogado quanto aos deveres em relação ao trato com o cliente, o sigilo profissional e à publicidade. Com isso, o exercício da advocacia passou a ser primado pela honra, decoro, veracidade, lealdade, dignidade e boa-fé, os princípios éticos constituem os valores éticos mais importantes da organização, pela obrigação de não abandonar o cliente e de abster-se de defender causa contrária à ética, à moral e declinar seu impedimento quando convidado pela outra parte, se tiver tomado conhecimento da causa.

Igualmente se exige uma atitude de maior retidão para aqueles que exercem a administração da justiça. O Código de Ética da Magistratura ${ }^{6}$ exige dos juízes o exercício da judicatura na estrita obediência aos critérios éticos de independência, imparcialidade, transparência, integridade física e profissional, diligência e dedicação, cortesia, prudência, sigilo profissional, conhecimento, dignidade, honra e decoro. Cunha (2010, p. 66) afirma que com a definição desses valores, o Brasil passa a materializar uma cultura judiciária mundial, pautada no fortalecimento da democracia, do respeito aos jurisdicionados e aos seus direitos, através de uma magistratura consciente e de um Poder Judiciário republicano, eficaz, justo e empenhado com o desenvolvimento do país.

Ainda no campo do direito, o Ministério Público representa uma instituição essencial à função jurisdicional do Estado e na defesa da democracia, consoante prescrito no art. 127,

\footnotetext{
${ }^{4}$ BRASIL. Ministério do Desenvolvimento, Indústria e Comércio Exterior. INMETRO. Responsabilidade social. Associação Brasileira de Normas Técnicas. ABNT NBR 16001:2004. Disponível em: < http://www.inmetro.gov.br/qualidade/responsabilidade_social/norma_nacional.asp>. Acesso em: 12 set. 2016.

${ }_{5}^{5}$ O Código de Ética e Disciplina da OAB, instituído conforme art. 33, da Lei no 8.906 , de 04 de julho de 1994, que dispõe sobre o Estatuto da Advocacia e a Ordem dos Advogados do Brasil (OAB). Disponível em: < http://www.planalto.gov.br/ccivil_03/leis/L8906.htm>. Acesso em: 17 set. 2016.

${ }^{6}$ Código de Ética da Magistratura, aprovado na $68^{a}$ Sessão Ordinária do Conselho Nacional de Justiça, em 06 de agosto de 2008, nos autos do Processo no 20080000007337. Disponível em: < http://www.cnj.jus.br/images /programas/publicacoes/codigo_de_etica_da_magistratura_nacional.pdf>. Acesso em: 17 set. 2016.
} 
do texto constitucional. Esses imperativos foram ratificados no atual Código de Processo Civil (Lei no 13.105/2015), no artigo 176, ao prescrever que “o Ministério Público atuará na defesa da ordem jurídica, do regime democrático e dos interesses e direitos sociais e individuais indispensáveis".

Embora não exista formalmente um Código de Ética do Ministério Público, sua atuação é orientada pelos critérios principiológicos estabelecidos na Constituição federal, na Lei Complementar $n^{\circ}$ 75/1993, que dispõe sobre a organização, as atribuições e o estatuto do Ministério Público e na Lei $n^{\circ}$ 8.625/1993 (Lei Orgânica Nacional do Ministério Público). Mazzilli (2005, p. 28) ao se reportar à ética exigida dos membros Ministério Público, inclui as normas de conduta que "compreende a análise de seus deveres e das correspondentes faltas funcionais (fatos que atentem, por exemplo, contra a dignidade, a probidade, o decoro, a lealdade, o zelo, a impessoalidade, a eficiência dos serviços afetos ao seu cargo)". Afinal, diz o autor, esses poderes não podem ser exercidos apartados da ética.

$\mathrm{Na}$ administração pública, o comportamento ético é exigido no âmbito da União, dos Estados, ${ }^{7}$ dos Municípios e do Distrito Federal por meio de Códigos de Ética Profissional. ${ }^{8}$ Neles são definidas as normas disciplinares e os comportamentos esperados dos servidores públicos. Os Tribunais de Contas da União ${ }^{9}$ e dos Estados, ${ }^{10}$ a Receita Federal $^{11}$ e as Secretarias de Fazendas estaduais instituem seus próprios códigos de ética.

A ética está presente no exercício da docência, já que essa relação também contribui com a formação dos indivíduos em sociedade. Bittar (2016, pp. 419-420) entende que a relação educando e educador deve se fundar “em princípios de respeito, diálogo e

\footnotetext{
${ }^{7}$ O Estado de Minas Gerais editou o Decreto n ${ }^{\circ}$ 46.644, de 6/11/2014, que dispõe sobre o Código de Conduta Ética do Agente Público e da Alta Administração Estadual. Disponível em: < http://www.conselhodeetica.mg.gov.br/images/documentos/Consolidado_NOVOCODIGOeDELIBERACOES.p df>. Acesso em: 17 set. 2016.

${ }^{8}$ Para exemplificar no âmbito da União vigora o Decreto n ${ }^{\circ}$ 1.171/1994 (Código de Ética Profissional do Servidor Público Civil do Poder Executivo Federal. Disponível em: < http://www.planalto.gov.br/ccivil_03 /decreto/d1171.htm>. Acesso em: 17 set. 2016; Decreto ${ }^{\circ}$ 6.029/2007, que instituiu o Sistema de Gestão da Ética do Poder Executivo Federal. Disponível em: < http://www.planalto.gov.br/ccivil_03/_ato20072010/2007/decreto/d6029.htm>. Acesso em: 17 set. 2016.

${ }^{9}$ O Tribunal de Contas da União instituiu o Código de Ética por meio da Resolução do TCU no 226, de 3 de novembro de 2010. Disponível em: 〈https://www.tcu.gov.br>. Acesso em: 17 set. 2016.

${ }^{10}$ Cite-se o TCE de Pernambuco instituiu seu Código de Ética pela Portaria $\mathrm{n}^{\circ} 252$, de 26 junho de 2012. Disponível em: < http://www.tce.pe.gov.br/internet/index.php/codigo-de-etica>. Acesso em: 17 set. 2016; Já o TCE do Rio Grande do Norte, instituiu o Código de Ética dos Servidores do Tribunal, por meio da Resolução no 026/2016, de 11/10/2016. Disponível em: < https://arearestrita.tce.rn.gov.br/as/Legislacao_site/download/ resolucoes_tce_rn/Resolu\%C3\%A7\%C3\%A3o_026_2016_C\%C3\%B3digo_de_\%C3\%89tica_de_Servidores.p df>. Acesso em: 17 set. 2016.

${ }^{11}$ O Código de Ética dos Agentes Públicos em exercício na Secretaria da Receita Federal do Brasil, foi instituído pela Portaria RFB n ${ }^{\circ}$ 773, de 24 de junho de 2013. Disponível em: < http://idg.receita.fazenda.gov.br/sobre/ institucional/arquivos-e-imagens/codigodeconduta>. Acesso em: 17 set. 2016.
} 
reciprocidade escolar-acadêmica". Nessa relação, o professor tanto pode influenciar a orientação cultural ou a busca do justo, quanto habilitar o aluno para o exercício ético de uma profissão e dos seus desafios. Em razão disso, acrescenta Bittar e Almeida (2016, p. 630) as ações do operador do direito repercutem e interferem no mundo fático, social, político, econômico, cultural e valorativo, o que por si só não dispensa que as práticas jurídicas sejam repensadas.

\section{1 Ética na medicina}

Analisando historicamente o nascimento da medicina social, Foucault (2011, pp. 8083) demonstra que o capitalismo propiciou a passagem de uma medicina privada para uma medicina coletiva através do controle social do corpo (força de trabalho) dos indivíduos. Essa socialização assegurou ao mercantilismo e ao Estado o controle da força ativa das populações (nascimento, mortalidade e índices de saúde) a cargo de uma polícia médica que passa a exercer o controle epidêmico ou endêmico das doenças (como lepra e a peste), nas cidades européias no século XVII e começo do século XIX.

Nesse ínterim, surge a normalização da prática e do saber médico. As universidades e os médicos passam a decidir sobre a formação médica, tornando a medicina e o médico os primeiros objetos de normalização. Hoje, o exercício da medicina está pautado por critérios de eticidade condizentes com os direitos da pessoa humana já que a relação médico paciente vai além do intercâmbio comercial. Para Pardo (2011) "la atencion sanitária tiene límites intrínsecos que no pueden ser traspasados: mutilar o dañar, causar perjuicios a terceras personas, proporcionar medicamentos o consejos fútiles, o que el médico actúe contra la propia consciência."

Outros aspectos fundamentais do desenvolvimento científico estão diretamente ligados à atitude do cientista. Conforme Bittar (2016, pp. 64-65) o cientista deve respeitar os diferentes saberes e culturas presentes e passadas, as sabedorias tradicionais/ancestrais com reconhecimento de suas conquistas sem marginalizar religiões, filosofias e culturas em nome de uma ciência moderna. A ética na ciência ganhou corpo após a Segunda Guerra Mundial, quando se esperava do cientista uma interrupção das suas investigações se o cálculo dos riscos não fosse claro, já que a possibilidade de fazer vítimas e de violar direitos das pessoas nessa relação era possível. O critério para esse limite é o respeito à dignidade da pessoa humana 
definido na Declarações das Nações Unidas de 1948, que toda ação humana deva considerar um fim eticamente justo, que sopese entre as conquistas das pesquisas e os limites da vida humana. Nesse aspecto, merece atenção o papel dos Comitês de Ética junto a hospitais, universidades, laboratórios e centros de pesquisas, no controle do exercício da ética na ciência. $^{12}$

O Conselho Federal de Medicina editou a Resolução nº 1931/2009 (Código de Ética Médica) elencando os princípios e normas éticas que devem ser obedecidas pelos profissionais da medicina, independentemente da função ou cargo que exerça, quanto aos direitos do médico. ${ }^{13} \mathrm{Na}$ mesma linha de normatização, o Conselho Nacional de Saúde, também editou a Resolução $n^{\circ}$ 466/2012 para tratar especificamente das diretrizes e das normas regulamentares de pesquisa com seres humanos. ${ }^{14}$

\section{2 Ética na criação intelectual}

Antes de discutir o aspecto ético da criação dos criadores e titulares de toda obra artística, literal, intelectual ou científica é preciso chamar atenção para o aspecto patrimonial

\footnotetext{
${ }^{12}$ No site da UFS pode ser consulta do regimento, composição, cronograma, instruções, notícias e princípios éticos desses Comitês. Disponível em: < http://www.ufs.br/pagina/4854>. Acesso em: 17 set. 2016.

${ }^{13}$ Merece destacar alguns princípios éticos fundamentais para o exercício da profissão de médico elencados nesta Resolução, como um serviço da saúde do ser humano e da coletividade, sem discriminação, com atenção à saúde do ser humano, com zelo, honra e dignidade, desempenhada com ética, aprimorada e usada de acordo com o progresso científico em prol do paciente, respeitando-o sem, jamais, causar-lhe sofrimento físico ou moral, sem caráter mercadológico, de lucro ou de finalidade política ou religiosa, com respeito ao sigilo das informações obtidas em virtude da função, com empenho no controle de riscos à saúde pública, ao ecossistema, à saúde e à vida, com respeito à educação sanitária e à legislação adstrita à saúde, com empenho na melhoria dos padrões de serviços médicos, com defesa da dignidade da profissão por remuneração justa e por condições do exercício ético-profissional da medicina, sem limitação dos meios científicos para o diagnóstico e tratamento, com respeito mútuo, consideração e solidariedade aos colegas, mas sem admitir contrariedade aos preceitos éticos, com responsabilidade pessoal pelos seus atos profissionais executados com culpa, sem transformar a sua atuação em relação de consumo, com aceitação de procedimentos indicados pelo paciente, se adequados ao caso e reconhecidos pela ciência, sem emprego de diagnósticos e terapias em casos terminais, com isenção e independência na produção do conhecimento, com respeitos às normas éticas e proteção aos sujeitos da pesquisa envolvendo seres humanos ou animais e sem permitir qualquer discriminação às pessoas em razão de herança genética, protegendo-as em sua dignidade, identidade e integridade. Disponível em< http://www.portalmedico.org.br/resolucoes/cfm/2009/1931_2009.htm>. Acesso em: 18 set. 2016.

${ }^{14}$ Esta Resolução no título III, que trata dos aspetos éticos da pesquisa quando envolve seres humanos, detalha os fundamentos éticos na pesquisa com seres humanos por envolver a dignidade e autonomia e respeito da pessoa que se submete a esta modalidade de pesquisa, quanto a sua autonomia e vontade de contribuir e permanecer, ou não, na pesquisa, através de manifestação expressa e livre, avaliação dos riscos e benefícios, tanto conhecidos como os potenciais, individuais ou coletivos, sempre buscando o máximo de benefícios e o mínimo de danos e riscos, evitando os riscos previsíveis e analisando a relevância social da pesquisa, considerando os interesses envolvidos, sem perder de vista o sentido de sua destinação sócio-humanitária, dentre outros preceitos éticos elencados. Disponível em: < http://conselho.saude.gov.br/resolucoes/2012/Reso466.pdf>. Acesso em: 18 set. 2016.
} 
(imaterial/intelectual) das obras no modelo capitalista. Bittar (2016, pp. 149-151) identifica duas dimensões nos direitos do autor: moral e patrimonial. A primeira se refere à proteção do autor e de sua personalidade extrínseca em obra de espírito e se caracterizam por serem personalíssimos, inalienáveis, irredutíveis, imprescindíveis e impenhoráveis. A segunda dimensão tem a ver com o lançamento da obra para o público e com a sua exploração econômica. Dizem respeito ao direito do titular fluir e retirar proveito econômico resultante da exploração estético-social da obra.

Assim, pode-se dizer que a garantia de propriedade intelectual se concretiza pelo uso do trabalho na sua elaboração. Conforme definição de Locke (1998, pp. 407-409) sobre a propriedade territorial, mas que se aplica à propriedade intelectual, cada homem tem uma propriedade em sua própria pessoa, a qual ninguém tem o direito que não ele mesmo. $\mathrm{O}$ trabalho do seu corpo e a obra de suas mãos é sempre propriedade dele. Qualquer coisa que ele retire da natureza, atrela-se ao mesmo com o seu trabalho e agrega-lhe algo, que se torna sua propriedade e com isso exclui o direito comum dos demais homens.

Nessa linha de intelecção de que o trabalho acadêmico representa uma propriedade intelectual, insta destacar o posicionamento de Hume (1995, p. 55) de que a propriedade do indivíduo é "qualquer coisa que ele, e apenas ele, pode utilizar legalmente". Quanto às regras para distinguir esses limites, afirma que se deve recorrer a estatutos, costumes, precedentes, analogias e centenas de outras circunstâncias, sejam elas constantes ou inflexíveis, variáveis e arbitrárias. Tanto é assim que o constituinte originário tratou de assegurar que "aos autores pertence o direito exclusivo de utilização, publicação ou reprodução de suas obras, transmissível aos herdeiros pelo tempo que a lei fixar" (art. 5, XXVII, da CF/88).

Não restando dúvida quanto à propriedade atribuída aos livros, ou a publicação de trabalhos acadêmicos que pode resultar na possibilidade concreta da configuração de crime, conforme artigo 184, do Código Penal Brasileiro (Decreto-Lei no 2848/1940). ${ }^{15}$ Reforçando essa ideia a Lei dos Direitos Autorais (Lei $n^{\circ}$ 9.610/1998) no artigo $3^{\circ}$ dispõe que os direitos autorais possuem natureza de bens móveis, ademais pertencem ao autor tanto os direitos morais como os patrimoniais sobre a obra que criou, diz o artigo 22 desta Lei.

\footnotetext{
${ }^{15}$ Reza o art. 184, do Código Penal Brasileiro: violar direitos de autor e os que lhes são conexos: Pena Reclusão, de 3 (três) meses a 1 (um) ano, ou multa. $\S 1^{\circ}$ Se a violação consistir em reprodução total ou parcial, com intuito de lucro direito ou indireto, por qualquer meio ou processo, de obra intelectual, interpretação, execução ou fonograma, sem autorização expressa do autor, do artista intérprete ou executante, do produtor, conforme o caso, ou de quem os represente: Pena - detenção, de 2 (dois) a 4 (quatro) anos, e multa. [...]". Disponível em: < http://www.planalto.gov.br/ccivil_03/decreto-lei/Del2848compilado.htm>. Acesso em: 11 set. 2016.
} 
Essas regras de proteção asseguram o desenvolvimento tecnológico por meio da criação de novos meios de produção industrial, comercial e de serviços. Nesse sentido, Comparato (2016, p. 347) lembra que no final do século XIX, os empresários capitalistas perceberam a importância econômica da ciência aplicada. Para criar vantagens competitivas, passaram a investir em pesquisas tecnológicas industriais. Com isso, as empresas iniciaram a contratação de profissionais cientistas e técnicos e a criar laboratórios industriais, o que resultou em novos processos de produção e de produtos, que passaram a ser patenteados e protegidos por instituições de dimensão mundial como a Organização Mundial da Propriedade Intelectual e a Organização Mundial do Comércio.

\section{A ÉTICA COMO PRINCÍPIO NORTEADOR NA CRIAÇÃO ACADÊMICA}

Ao longo da história, o plágio sempre recebeu reprovação social. Coelho (2009, pp. 134-135) informa que na antiguidade greco-romana a descoberta de plágio ou cópia causava ao plagiador repúdio público, desonra e desqualificação nos meios intelectuais. O ponto inicial para a regulação do direto autoral foi a invenção da imprensa, por Gutemberg, no século XV, quando as ideias e as informações ganharam escala industrial e intensa reprodutibilidade. Mas foi com a Revolução Industrial que a produção literal passou a merecer proteção.

Kant (2003, pp. 134-135) já vislumbrava a publicação de livro por editor não autorizado, como passível de criminalização. Dizia ele que se da o nome de autor de um livro àquele que fala ao público em seu próprio nome. E de editor, aquele que, por meio de um escrito, discursa publicamente em nome de outrem (do autor). Sendo legítimo quando o faz com a permissão do autor e ilegítimo quando não autorizado. Portanto, se um editor fala ao público por meio de uma edição de sua iniciativa, sem o respectivo mandato do autor, comete crime de roubar os lucros que o editor autorizado pelo autor, poderia e teria obtido do uso de seu direito. Com isso, protegem as ciências, as artes e assegura a propriedade daqueles que nelas trabalham contra o roubo, medida primordial para a segurança do comércio, da indústria e das vias de comunicação.

Hegel (1997, pp. 67-68) entende que o produto do espírito também tem por fim fazer-se representar por outros indivíduos como memória e pensamento assimilados. Nessa transmissão transformam o que aprenderam em coisa alienável - pois aprender não é saber de 
memória, mas apreender com o pensamento as ideias dos outros, e pensar de acordo com outrem, também é aprender. Todavia, a programação das ideias, do ensino e dos escritos das ciências, tem por finalidade e dever a multiplicação de ideias obtidas de outrem. A questão é saber até que ponto a repetição de uma obra literária configura ou não plágio, por ser uma situação que não é suscetível de determinação por uma regra fixa, em consequência, não pode ser definida jurídica e legalmente. O plágio devia ser uma questão de honra e por esta razão não ser cometido.

Eco (1998, p. 34) entende que é roubo de trabalho científico, a utilização de dados e experimentos que somente poderiam ser obtidos mediante específica experiência, do mesmo modo a utilização de dados estatísticos do autor nunca coletados antes, sem citação da fonte ou a utilização de traduções de textos, ainda não traduzidos.

Ao analisar o plágio sob o enfoque moral, Hegel (1997, p. 69) destaca de maneira crítica

\begin{abstract}
Quanto aos efeitos que a honra deverá ter contra o plágio, de tal modo se deixou de ouvir a palavra plágio ou roubo intelectual que temos de concluir ou que a honra já eliminou o plágio, ou que o plágio deixou de ser atentatório da honra e desapareceu o correspondente sentimento, ou, então, que a menor alteração numa forma exterior se tem já como uma tão alta originalidade, um tão autônomo pensamento, que a ninguém ocorre a idéia de plagio.
\end{abstract}

Mas, em se tratando de plágio propriamente dito, além da reprovabilidade da conduta moral que este enseja, outros reflexos podem acarretar na vida laboral do plagiador. Foi o que ocorreu com uma professora da Universidade Federal de Roraima que obteve seu doutoramento copiando uma tese de outra docente da Universidade Federal do Rio de Janeiro. E em razão disso o Tribunal de Contas da União (TC-018.756/2014-0) ${ }^{16}$ suspendeu os pagamentos da gratificação por titulação e exonerou do cargo comissionado de diretora, a professora que elaborou sua tese doutoral considerada como plágio.

A jurisprudência tem assegurado o direito à indenização ao autor plagiado. A exemplo disso, o caso de elaboração e distribuição de apostila plagiada de livro sem a devida permissão autoral, conforme excerto da ementa da decisão proferida pelo Tribunal Federal da Primeira Região: ${ }^{17}$ "Civil. Processo Civil. Plágio. Reprodução de Obra Literária sem autorização. Preliminares Rejeitadas. Indenização por danos materiais e morais. Cabimento.

\footnotetext{
${ }^{16}$ O voto do Relator Marcos Bemquerer Costa, no Acórdão no 187/2015-TCU-Plenário. Disponível em: < www.tcu.gov.br/Consultas/Juris/Docs/judoc/Acord/../AC_0187_04_15_P.doc>. Acesso em: 17 set. 2016.

${ }^{17}$ Apelação Cível no 2006.37.00.005685-1/MA - TRF1 - Terceira Seção. Rel. Des. Federal Kassio Nunes Marques. e-DJF1 12 set. 2016. Disponível em: < http://jurisprudencia.trf1.jus.br/busca/>. Acesso em: 17 set. 2016.
} 
Sentença mantida. Como também a reprodução de parte de obra intelectual em sites sem a autorização e referência autoral, consoante decisão do Tribunal de Justiça de São Paulo. ${ }^{18}$

Ainda sobre a questão ética na elaboração de trabalho científico, Eco (1998, pp. 33 34) menciona caso interessante, porém em relação ao docente orientador, quando este sugere um tema que conhece pouco e sobre o qual quer se aprofundar e alargar os horizontes, utilizando o discente/orientando para fazer seus trabalhos de pesquisas. Embora legítimo, violenta o discente quando este não tem interesse sobre o tema e elaborará um trabalho simplório, enquanto o professor em sua tese definitiva, sequer citará o aluno, porquanto o discente não evidenciou nenhuma ideia concisa. Neste caso, o professor promove uma desonestidade ao pôr o estudante a trabalhar e utilizar o seu trabalho como se fosse seu.

A ética, portanto deve ser ínsita ao trabalho de pesquisa, tanto na relação do pesquisador com seus pares, do orientador com o orientando e do pesquisador com o objeto estudado. Neste último caso, adverte Richardson (1999, pp. 262-263) que nas pesquisas de campo ou exploratórias, como as pesquisas sociais ou humanitárias em que o observador participa e se colocar em nível dos outros elementos humanos integrantes do fenômeno estudado, como se membro fosse desse grupo, o pesquisador deve deixar claro quais são suas intenções para legitimar o ingresso formal e ser aceito no grupo. Do contrário, ele fere o preceito ético de respeito à comunidade e passa a ser considerado espião, já que a comunidade desconhece suas pretensões verdadeiras, podendo rejeitá-lo definitivamente.

\subsection{A tecnologia como facilitador/controlador do plágio acadêmico}

Hoje o pesquisador conta com a poderosa ferramenta da internet para realizar sua pesquisa. Além disso, a rede possui sites que ofertam o serviço de confecção de trabalhos de conclusão de cursos como: monografias, dissertações e teses prontas, para quem se disponha a pagar pelo trabalho pronto e acabado. Disso cabe questionar: sendo a autoria uma propriedade, a venda pelo autor de um trabalho pronto é antiético? Para responder, necessário se faz algumas ponderações. Primeiro, o autor não poderá alegar plágio em relação ao

\footnotetext{
${ }^{18}$ Colaciona-se excerto da ementa: AÇÃO DE INDENIZAÇÃO POR DANOS MORAIS E MATERIAIS. [...] Reprodução de trecho de obra intelectual da autora pela ré em seu website sem autorização ou referência de autoria. Configuração de plágio. Lesão ao direito da personalidade da autora que decorre dos próprios fatos narrados. [...] (APELAÇÃO n 0007740-25-2013.8.26.0011. TJSP - 7 Câmara de Direito Privado. Rel. Desemb. Mary Grün. DJ 25 nov. 2015. Disponível em: < http://esaj.tjsp.jus.br/cjsg/getArquivo.do?cdAcordao= 9107597\&cdForo=0\&vlCaptcha $=$ bfmrv>. Acesso em: 17 set. 2016.
} 
adquirente, posto que transmitiu a este a propriedade intelectual. Segundo, ao encomendar um tema, o adquirente o fez com que propósito?

E mais, até que ponto pagar para alguém fazer uma pesquisa de campo é antiético? Primeiro, é possível adquirir um trabalho pronto para outros fins que não seja o de obter qualquer grau de conclusão de curso, porque neste caso, a realização do trabalho chancela o examinado. Segundo, a ideia do trabalho acadêmico é inserir o aluno no campo da pesquisa e do debate de temas e com isso familiarizá-lo com o universo da escrita acadêmica que prima pela clareza, objetividade e precisão das informações.

Richardson (1999, p. 24) entende que o trabalho de monografia começa com as anotações que se tornarão relatório parcial, “que deve ser lido pelo orientador.” Já Eco (1998, p. 117) acha que a primeira leitura do texto do aluno deve feita pelo orientador que dará as sugestões necessárias para que o trabalho seja formatado dentro do que a comunidade acadêmica definiu como o melhor modelo. As correções, porventura sugeridas, não irão impingir na falta de dever ético.

Tentando coibir a ocorrência de plágio, a Coordenação de Aperfeiçoamento de Pessoal de Nível Superior (Capes), em 04 de janeiro de 2011, publicou uma orientação para que as instituições de ensino públicas e privadas do país promovam políticas de conscientização sobre a propriedade intelectual, bem como a adoção de procedimentos para coibir a prática de plágio na elaboração de trabalhos acadêmicos. ${ }^{19}$

Essa orientação se baseou na proposta/recomendação aprovada pela Comissão Nacional de Relações Institucionais da OAB, Seccional do Ceará ( $\left.n^{\circ} 2010.19 .07379-01\right),{ }^{20}$ na qual recomenda o uso de softwares de que realizam leitura eletrônica de textos e buscam em diversos sites na web a similitude de frases ou parágrafos copiados sem a devida referência. Isso tem como finalidade coibir o ato ilegal de apropriação indevida da obra de terceiros. A recomendação aborda o comércio ilegal de monografias e trabalhos prontos, negociados livremente aos interessados em sites da internet.

A sociedade de informação possibilitou a abertura de diversas alternativas e experiências de comunicação para aqueles que denominam a escrita e a leitura. Livros e os materiais científicos passaram a ser disponibilizados na web em formato digital, favorecendo

\footnotetext{
${ }^{19} \mathrm{O}$ texto dessa orientação está publicado na internet. Disponível em: < https://www.capes.gov.br/images/ stories/download/diversos/OrientacoesCapes_CombateAoPlagio.pdf>. Acesso em: 13 set. 2016.

${ }_{20} \mathrm{O}$ texto integral desta recomendação encontra-se publicado na web. Disponível em: <https://www.ucb.br/sites/000/20/CombateP'lagioDocumentoOAB.pdf>. Acesso em: 13 set. 2016.
} 
ao cidadão o acesso a infinitas fontes de informação. Para usá-las é necessário cautela e discernimento não só para selecioná-las, mas para entender que, na ação do uso da ideia está implicada a relação de autoria que na pesquisa deve ser informada. Carvalho (2014, p. 11) adverte que em muitos casos, a manipulação da informação não se mostra evidente.

Bittar (2016, pp. 131-132) ao tratar dos critérios eticidade na elaboração de uma pesquisa, defende que todo pesquisador na elaboração de texto com pretensões científicas deve atuar com honestidade intelectual, atuação ética e proba na condução dos trabalhos, em respeito aos ditames da Lei $\mathrm{n}^{\circ}$ 9.610/1998 que define o pesquisador pela vontade de dividir sua opinião e o espaço do conhecimento com os demais pesquisadores, compartilhamento do conhecimento com interação na esfera pública, capacidade de construir conhecimento fecundo com ações em prol da dignidade da pessoa humana, fomento da pesquisa como mecanismo de atuação do conhecimento responsável, afastamento dos autoritarismos doutrinários, permanente produção comunitária e coletiva, democracia no uso e acesso das ideias.

Assim, os textos com carência de citação e ausência de bibliografia demonstram falta de localização de referência teórica, pobreza de diálogo, certa arrogância do pesquisador, por se achar capaz de elaborar textos sem o intercâmbio com a comunidade científica - autores do passado, do presente, nacionais e estrangeiros. Por outro lado, a propriedade intelectual de qualquer pesquisa se deve em primeiro lugar, ao próprio discente, pois como lembra muito bem Hume (1995, p. 223) temos um dever para conosco mesmos e isso é reconhecido até pelo mais vulgar sistema de moral, e deve ser importante examinar esse dever a fim de descobrir se ele tem alguma afinidade com aquele que temos para com a sociedade.

Vale lembrar a lição de Comparato (2016, pp. 504-505) sobre a diferença entre a norma ética e a regra técnica. Para ele, os princípios éticos são normas que forçam o indivíduo a agir em função do valor do bem almejado por sua ação, ou de um objetivo último que lhe dê sentido à vida humana; e não de um interesse estritamente particular, que não se compartilha com a comunidade. Esse valor objetivo deve ser pensado ao mesmo tempo: no indivíduo, no grupo social, no povo ou na humanidade. De outra parte, a norma técnica refere-se aos meios hábeis de se almejar um resultado, que objetivamente pode ser bom ou mau para uns ou para toda a coletividade. Posto que a regra técnica, em si mesma, é eticamente indiferente e guia-se pelo valor da utilidade ou eficiência dos mecanismos na elaboração de um resultado.

Em sentido convergente, Kant (2007, p. 51) explica que todas as ciências têm uma parte prática, composta por problemas com certa finalidade para o indivíduo e de imperativos 
de destreza que indicam como atingi-la. Porém, não importa saber se a finalidade é razoável e boa, mas tão-somente o que é necessário fazer para alcança-la. Pois somente uma "ação sem qualquer inclinação, simplesmente por dever, só então é que ela teria o seu autêntico valor moral" (KANT, 2007 p. 28).

E nesse modo de atuar, o pesquisador não deve se afastar dos critérios morais e éticos em respeito à propriedade intelectual, quando da utilização de qualquer ideia de outro em seu trabalho acadêmico, esteja ela publicada em qualquer suporte. Assim, se por um lado a tecnologia incrementa e facilita o "copiar" ( $c$ trl c) e o "colar" (ctrl v), também facilita a investigação instantânea sobre a utilização de ideias, frases ou parágrafos de obras sem o devido crédito autoral, bastando para isso uma pesquisa aos sites que realizam a verificação se o texto apresentado contém suspeita de plágio com algum documento (nos formatos: doc, pdf, rft, html, txt etc.) constante da rede mundial de computadores. ${ }^{21}$ Para tanto, constam das regras da $\mathrm{ABNT}$ o formato de citação para estes tipos documentos que devem ser, citados não só como uma imposição resultante da decodificação, mas, sobretudo, como uma ação resultante de um dever moral de todo autor como norma em si mesma.

\subsection{Regras da ABNT como norma de respeito à ética}

Advertimos que está fora dos objetivos deste artigo tratar das inúmeras aplicações das normas elaboradas pela Associação Brasileira de Normas Técnicas - ABNT ou o seu emprego prático nos diversos ramos da indústria, ciência e tecnologia. Interessa-nos aqui sua utilização em resposta à busca do autor em identificar aquele com quem dialoga, seu autor e seu contexto. Daí a importância da aplicação da norma ou das normas pertinentes à elaboração de trabalhos de pesquisas na seara acadêmica.

Considerando a história da normalização do "saber", Dias (2011, p. 7) informa que “a codificação do conhecimento tecnológico, por diversas razões de ordem prática e por considerações de lucro e de segurança, sempre foi a exceção nas sociedades humanas e não a regra”. No Brasil não seria diferente. Mas o avanço da ciência e do comércio mundial exigiu a institucionalização de normas técnicas, com maior ênfase, após a expansão das relações

\footnotetext{
${ }^{21}$ Dentre milhares de sites gratuitos, cite-se: http://www.checkforplagiarism.net, http://www.copyspider.com.br, http://www.plagiarismcombat.com, http://www.plagiarismadvice.org, http://www.plagiarismdetect.com/, http://plagiarisma.net, http://www.plagium.com, http://www.plagius.com, http://www.scanmyessay.com. Cite-se ainda os sites pagos: http://www.checkforplagiarism.net, http://www.ephorus.pt, http://www.turnitin.com.
} 
econômicas entre as nações, envolvendo produtos de maior sofisticação e conteúdo técnico. Com essa situação, surge a necessidade de compartilhamento de estruturas tecnológicas e sociais. A norma técnica aparece com a revolução industrial e com os mercados mundiais desses produtos. Nas últimas décadas do século XIX ela é impulsionada pelas pressões canalizadas pelo comércio e pelo consumo para que houvesse maior harmonização entre processos e produtos.

Ainda segundo Dias (2011, p. 30) setores da siderurgia e da energia elétrica na Europa e nos Estados Unidos, tornaram indispensável a normalização em seus processos de produção. Informa também que no Brasil isso ocorreu com o desenvolvimento da construção civil e de um campo técnico especifico: a utilização do concreto armado. Do ponto de vista econômico era uma solução para reduzir o uso de materiais siderúrgicos na construção, já que o país produzia pouco ferro e aço. Dias (2011, p. 45) ainda acrescenta que é necessário considerar ainda a ligação dos acadêmicos de engenharia nacional com a Europa, onde essa tecnologia era mais desenvolvida e o concreto se revelou importante para as condições ambientais e da natureza dos materiais usados na construção civil.

Nesse contexto nasce a ABNT, como modelo de compras dos governos e de suas empresas o que serviu de estímulo para a normalização de produtos e o desenvolvimento de laboratórios de ensaios (DIAS, 2011, pp. 49-51). As normas são demonstração da maturidade técnica da engenharia nacional e da preocupação dos gestores do Estado com a modernização da administração pública, como entidade permanente e de âmbito nacional, responsável pela normalização. Assim, adquiriu prestígio nacional e internacional, e nas últimas décadas do século XX, com a prosperidade econômica e a globalização impulsionou a exigência de normalização em âmbito mundial, fazendo surgir demandas de certificação para as áreas de gestão de segurança em turismo de aventura, gestão sustentável, em meios de hospedagem, além dos campos tradicionais da qualidade em sistema de gestão ambiental, de segurança e saúde ocupacional e sistemas de gestão de responsabilidade social (DIAS, 2011, pp. 83-99).

Saliente-se que as normas técnicas da ABNT estão presentes nas mais diversas áreas, desde estrutura de concreto, símbolos de sinalização pública, caderno escolar ou sacolas plásticas usadas nos supermercados, como também nas relações entre os cidadãos, empresas, associações e governo. Aliás, as normas surgem de demandas da sociedade, posto que o processo de elaboração de uma norma técnica pode ser iniciado por qualquer pessoa, empresa ou organização regulamentadora ligada ao assunto a ser normalizado e envolve governo, 
indústria, organizações não governamentais (ONG) e qualquer interessado, gerando projeto de norma quando houver consenso. De modo que, há 76 anos a ABNT vem atendendo demandas da sociedade para a elaboração de normas técnicas e contribuindo para o progresso tecnológico da sociedade ABNT (2016, p. 18).

Assim, a normalização técnica editada pela ABNT, conforme consta em seu site www.abnt.org.br tem a missão de:

Prover a sociedade brasileira de conhecimento sistematizado, por meio de documentos normativos, que permitam a produção, a comercialização e o uso de bens e serviços de forma competitiva e sustentável nos mercados interno e externo, contribuindo para o desenvolvimento científico e tecnológico, proteção do meio ambiente e defesa do consumidor.

De outra parte, quanto à análise das normas da ABNT e ao seu emprego na elaboração de textos acadêmicos, o pesquisador deve ter em mente que a busca da inovação, por meio de pesquisas, em qualquer área, deve ser apresentada em formato próprio para o meio acadêmico, o qual é determinado por meio de normas técnicas elaboradas pela ABNT. Pensar de modo diverso é admitir, na prática, o caos - cada pesquisador criaria seu próprio modo e estilo de apresentação de seu texto.

Além disso, o fato de explicitar a forma correta de promover as referências e citações de obras na elaboração de textos acadêmicos, em última análise, consubstancia o respeito ao direito à propriedade imaterial e autoral legalmente prevista e também em um agir moralmente perante a comunidade. Como salientado por Rouanet (2013, p. 65) as razões públicas são impulsionadoras de um agir moralmente na sociedade plural contemporânea, na qual não se espera somente a concordância de todos sobre os valores morais básicos. Esperase que todos obedeçam às leis, mas para que cumpram a lei é necessário primeiro que todos estejam particularmente convencidos de que devem obedecê-la.

Daí porque, defende-se a opção de escolha do pesquisador em elaborar um texto dissertativo dentro das normas da ABNT, não somente como obrigação cogente em virtude da normatividade, mas como conduta ética por responsabilidade e não por mera convicção, como idealizou Weber, portanto, como conduta moral subjetiva de agir em si mesma.

De maneira que não resta alternativa outra, que não exigir do autor de um texto, com pretensões de expor e transmitir ao mundo científico e acadêmico, seu cotejo com determinado assunto, que o faça por auto deliberação de fazer com o máximo de respeito à propriedade intelectual dos seus pares, exatamente para exigir dos outros que se portem de igual modo quanto ao seu texto elaborado/apresentado. 
Numa perspectiva kantiana do imperativo categórico é o dever de atuar de tal forma que esse agir seja publicizado e que possa se tornar norma universal. No âmbito do uso das normas da $\mathrm{ABNT}$, se exige condutas padronizadas a serem adotadas por todos aqueles que participam e compartilham dos conhecimentos científicos. Aliás, reflete um contrassenso, alguém querer transmitir aos outros um conhecimento, um estudo ou uma ideia por intermédio de um trabalho de pesquisa, se o próprio autor transmite em si uma enganação, uma farsa, um engodo, um plágio. Nesse aspecto, lembra Weber (2013, p. 114) que "nenhuma ética pode dizer-nos a que momento e em que medida um fim moralmente bom justifica os meios e as consequências moralmente perigosas."

\section{CONSIDERAÇÕES FINAIS}

Este ensaio demonstrou que mesmo diante da dualidade humana: bem e mal, virtude e vício, os critérios morais devem pautar os comportamentos individuais para uma melhor convivência humana, bem como nas mais diversas profissões, a ética é regra fundante e de suma importância para o contexto dessas relações sociais envolvidas às quais se exige as mais rígidas normas éticas e morais.

Averiguou-se que não somente as normas positivadas, mas também as regras morais e éticas servem para frear o ímpeto da realização de condutas direcionadas para comportamentos destoantes com a falta de respeito ao direito de propriedade patrimonial do autor e também com o desenvolvimento de comportamentos apartados de conteúdo moral na elaboração e execução de todo e qualquer trabalho artístico, literário ou científico. Ademais, examinou-se que o direito autoral encontra guarida na norma constitucional e infraconstitucional, com fincas a resguardar os direitos de propriedade imaterial do autor, com sanções (materiais e danos morais) aos transgressores dessas normas.

Demonstrou-se que as normas da ABNT, nas mais diversas áreas do conhecimento humano, representam a concretização de um modelo de regras técnicas que auxiliam os inventores na descrição do saber. E na seara acadêmica elas servem de norte para autores na formatação e apresentação de trabalhos acadêmicos e também como elemento concretizador do respeito ao patrimônio autoral dos autores.

Conclui-se, portanto que todo autor deve fazer uso das normas técnicas da ABNT pela simples inclinação do seu uso em si mesma e que a finalidade não deve estar em uma 
norma externa ou numa finalidade exógena ao pesquisador, mas, tão somente na ética da responsabilidade subjetiva do mesmo, de que seu atuar se infirma em uma íntima persuasão de um atuar por dever em si e em momento anterior à decisão do emprego dessas normas.

\section{REFERÊNCIAS}

ALMEIDA, Daniel Freire e. A tributação do comércio eletrônico nos Estados Unidos da América e na União Europeia. São Paulo: Almedina, 2015.

ASSOCIAÇÃO BRASILEIRA DE NORMAS TÉCNICAS. 76 anos contribuindo com a sociedade. Boletim ABNT. set./out. v. 13 no 153. Rio de Janeiro: ABNT, 2016. Disponível em: http://abnt.org.br/images///boletim/Boletim_ABNT_153_set_out_2016_completa_Net .pdf>. Acesso em: 12 set. 2016.

NBR 16001:2004. Responsabilidade social - Sistema da gestão - Requisitos. Rio de Janeiro, 2004. Disponível em: <http://www.inmetro.gov.br/qualidade/responsabilidade_social /norma_nacional.asp>. Acesso em: 12 set. 2016.

BITTAR, Eduardo C. B. Metodologia da Pesquisa Jurídica: teoria e prática da monografia para os cursos de Direito. 14. ed. São Paulo: Saraiva, 2016.

. Curso de Ética Jurídica: ética geral e profissional. 13. ed. São Paulo: Saraiva, 2016.

.; ALMEIDA, Guilherme Assis de. Curso de Filosofia do Direito. 12. ed. ed. rev. e ampl. São Paulo: Atlas, 2016.

BRASL. Decreto-Lei no 2.848, de 7 de dezembro de 1940. Código Penal. Disponível em: <http://www.planalto.gov.br/ccivil_03/leis/L9610.htm>. Acesso em: 13 set. 2013.

Lei $n^{\circ}$ 9.610, de 19 de fevereiro de 1998. Altera, atualiza e consolida a legislação sobre direitos autorais e dá outras providências. Disponível em: https://www.planalto.gov.br/ ccivil_03/leis/L9610.htm>. Acesso em: 13 set. 2013.

CARVALHO, Ana Cristina Azevedo P. Marco civil da internet no Brasil: análise da lei 12.965/14 e do direito de informação. Rio de Janeiro: Alta Books, 2014.

COELHO, Luís Alberto G. Gomes. A proteção à propriedade intelectual como problema jurídico. In: GUNTHER, Luiz Eduardo. (coord.) Tutela dos direitos da personalidade na atividade empresarial. Curitiba: Juruá, 2009.

COMPARATO, Fábio Konder. Ética: direito, moral e religião no mundo moderno. 3. ed. São Paulo: Companhia das Letras, 2016.

CONSELHO FEDERAL DE MEDICINA. Aprova o Código de ética Médica. Resolução no 1931, de 17 de setembro de 2009. Publicada no D.O.U. de 24 de setembro de 2009, Seção I, p. 90. Disponível em< http://www.portalmedico.org.br/resolucoes/cfm/2009/1931_2009. htm>. Acesso em: 18 set. 2016. 
CONSELHO NACIONAL DE SAÚDE. Aprova as diretrizes e normas regulamentares de pesquisa envolvendo seres humanos. Resolução no 466, de 12/12/2012. Disponível em: <http://conselho.saude.gov.br/resolucoes/2012/Reso466.pdf>. Acesso em: 18 set. 2016.

CUNHA, José Ricardo. O juiz, a ética e o direito. In: CUNHA, José Ricardo (Org.). Poder Judiciário: novos olhares sobre gestão e judiciário. Rio de Janeiro: FGV, 2010.

DIAS, José Luciano. História da normalização brasileira. Rio de Janeiro: ABNT, 2011.

ECO, Umberto. Como se faz uma tese. Tradução Gilson César Cardoso de Souza. 14. ed. São Paulo: Perspectiva, 1998.

FONSECA, Márcio Alves da. Michel Foucault e a constituição do sujeito. São Paulo: EDUC, 2003. Disponível em: < https://books.google.com.br/books?id=Qmegf4V14YAC\& printsec $=$ frontcover $\& \mathrm{hl}=\mathrm{pt}-\mathrm{R} \&$ source $=\mathrm{gbs} \_\mathrm{ge} \_$summary_r$\& \mathrm{cad}=0 \# \mathrm{v}=$ onepage $\& \mathrm{q} \& \mathrm{f}=$ false $>$. Acesso em: 22 out. 2016.

FOUCAULT, Michel. Microfísica do poder. Tradução de Roberto Machado. 29. reimpressão. Rio de Janeiro: Edições Graal, 2011.

Historia da sexualidade 2: o uso dos prazeres. Tradução de Maria Tereza da Costa Albuquerque. 9. ed. Rio de Janeiro: Edições Graal, 2001.

HEGEL, Georg Wilhelm Friedrich. Princípios da filosofia do direito. Tradução de Orlando Vitorino. São Paulo: Martins Fontes, 1997. (Clássicos)

HUME, David. Uma investigação sobre os princípios da moral. Tradução de José Oscar de Almeida Marques. Campinas, SP: UNICAMP, 1995. (Coleção Repertórios)

KANT, Immanuel. A metafísica dos costumes. Tradução Edson Bini. Bauru, SP: EDIPRO, 2003. (Série Clássicos Edipro).

. Fundamentação da metafísica dos costumes. Tradução de Paulo Quintela. Lisboa: Edições 70, 2007.

LOCKE, John. Ensaio acerca do entendimento humano. Tradução de Anoar Aiex. São Paulo: Nova Cultural, 2000.

. Dois Tratados Sobre o Governo. Tradução de Julio Fischer. São Paulo: Martins Fontes, 1998. (Clássicos)

MAZZILLI, Hugo Nigro. Ministério Público. 3. ed. São Paulo: Damásio de Jesus, 2005.

MORAIS, Regis de. Realismo e esperança: uma reflexão ética. In: NALINI, José Roberto (Org.). Magistratura e ética: perspectivas. São Paulo: Contexto, 2013.

NADER, Paulo. Curso de Direito Civil: responsabilidade civil. Vol. 7. 6. ed. ver. atual. e ampl. Rio de Janeiro: Forense, 2016. 
PARDO, Antonio. La Ética em la Medicina. Revista Persona y Bioética. Bogotá, Universidade de La Sabana, vol. 15. Número 2, p. 166-183, dez. 2011. Disponível em: < http://personaybioetica.unisabana.edu.co/index.php/personaybioetica/article/view/2158>. Acesso em: 18 set. 2016.

RICHARDSON, Robert Jarry. Pesquisa Social: métodos e técnicas. 3. ed. São Paulo: Atlas, 1999.

ROUANET, Luiz Paulo. Por que devemos agir moralmente?. In: NALINI, José Renato. (Org.). Magistratura e Ética: perspectiva. São Pulo: Contexto, 2013.

SANTOS, Fernando de Almeida. Ética empresarial: políticas de responsabilidade social em 5 dimensões. Sã Paulo: Atlas, 2015.

WEBER, Max. Ciência e política: duas vocações. Tradução de Leonidas Hegenber e Octany Silveira da Mota. 20. ed. São Paulo: Fundação Getúlio Vargas, 2013. 